\title{
RELAÇOES ETNICO-RACIAIS E CIDADANIA: GRUPOS DE PESQUISA E NETWORKS PELA TRANSFORMAÇÃO DE GRILHOES EM ALIANÇAS
}

\section{ETHNIC-RACIAL RELATIONS AND CITIZENSHIP: RESEARCH GROUPS AND NETWORKS FOR THE TRANSFORMATION OF CHAINS IN ALLIANCES}

Ronilda Iyakemi Ribeiro

RIBEIRO, R I. Relações Étnico-Raciais e Cidadania: Grupos de Pesquisa e Networks pela Transformação de Grilhões em Alianças. Rev. Bras. Cresc. Desenu Hum., São Paulo, 9(2), 1999.

Resumo: Neste trabalho descreve-se e discute-se a experiência do Grupo de Estudos interdisciplinares das Ancestralidades Africanas e Cidadania, um grupo de orientação de pesquisas de mestrado e doutorado da Universidade de Sao Paulo, que busca contribuir para amadurecer o debate sobre políticas de ação afirmativa para valorização da África, dos africanos e afrodescendentes. Para expor parte da experiência desse grupo de estudos são abordados os seguintes tópicos: (a) o conceito de networlc; (b) as relações entre identidade pessoal e pertença a networks organizados em torno da temática racial.

Palavras-chave: Afrodescendentes; Ação afirmativa e Cidadania.

A herança compartilhada por afrodescendentes nos países da diáspora africana pode vir a constituir excelente instrumento de união no interior desse megagrupo que visa a promoção de igualdade de direitos e oportunidades em contextos sócio-culturais onde o preconceito e a discriminação étnico-raciais geram condições de desrespeito aos princípios de justiça e igualdade. Para a realização desse ideal concorrem esforços de grupos de pequeno, médio, grande e muito grande porte (networks). Nesses grupos, o necessário processo de ampliação de consciências supõe certamente uma ação sobre as identidades das pessoas que compõem os grupos de trabalho.

Aqui descrevo, situada no contexto dos networks voltados para a ação e reflexão sobre relações étnico-raciais e direitos humanos, algo da experiência do GEAAC - Grupo de Estudos Interdisciplinares das Ancestralidades Africanas e Cidadania, um grupo de orientação de pesqui- sas de mestrado e doutorado da Universidade de São Paulo que, transformado em espaço para o compartilhar de experiências e reflexões, terminou por definir novos objetivos, entre os quais o de contribuir para amadurecer o debate sobre políticas de ação afirmativa para valorização da África, dos africanos e afrodescendentes.

Como ganhos secundários - não de importância menor - observou-se efeito altamente positivo do processo grupal sobre a autoestima e autoimagem dos afrodescendentes que integram o grupo. Outros membros, não afrodescendentes que trabalham com essa temática, alcançaram melhores condições de reflexão e ação rumo aos objetivos gerais dos networks dos quais esse Grupo de Pesquisa (GP) constitui apenas uma pequena parcela.

Observou-se, ainda, um aumento da eficácia individual e grupal no referente à produção de trabalhos científicos que deverão trazer subsídios às necessárias e urgentes transformações sociais.

1 Doutora em Psicologia e Antropologia (us $\wedge$ P). Coordenadora do Grupo de Estudos das Ancestralidades Aíricanas e Cidadania - GEAAC/USP. End.: Av. Manoel Martins, 119 - CEP 07600-000 - São Paulo - SP - E-mail: iyakemi@usp.br. 
Para expor parte da experiência desse GP abordo, ainda que brevemente, os seguintes tópicos: (a) considerando que um GP também é um Grupo de Trabalho (GT) inserido num network, explicito o conceito de network; (b) interessada pelo processo individual que ocorre articulado ao grupal, abordo o tema das relações entre identidade pessoal e pertença a networks organizados em torno da temática racial.

\section{NETWORKS}

Networks são redes de conexões. Os recursos desenvolvidos pela tecnologia a favor da comunicação à distancia possibilitaram a organização em macro-grupos e mega-grupos. As pessoas podem agora unir-se em redes de muitos tamanhos, sendo a maior delas o grande grupo chamado humanidade. Podemos identificar sub-agrupamentos na grande malha de relações humanas, desde a parceria interpessoal, passando pelos grupos pequenos, como o familiar; médios, como o da instituição na qual trabalhamos; grandes como a nação ou, ainda, muito grandes, como o de indivíduos preocupados, por exemplo, com a Educação em todo o mundo. Tais estruturas grupais possuem características e dinamismos próprios, com distintos mecanismos de comunicação. Cada um de nós integra, sem dúvida, vários grupos e, a partir do momento que alcanço consciência de pertença a um macro-grupo ou mega-grupo e estabeleço conexões com meus pares, pode-se dizer que passo a integrar uma rede de conexões.

LIPNACK \& STAMPS (1992) sugerem algumas imagens possíveis de network sistema físico semelhante a uma arvore ou rede; sistema de nodos (pontos) e elos (linhas unindo-os); comunidade não-geográfica. Quando uma pessoa necessitada de algo contata alguém que dispõe de recursos, se estabelece uma conexão. Pois bem, trabalhar em network significa conectar-se com pessoas para associar idéias e revursos a necessidades.

\section{IDENTIDADE E PERTENCAA GRUPOS DE TRABALHO (GT) E NETWORKS ORGANIZADOS EM TORNO DA TEMÁTICA RACIAL}

Os africanos e seus descendentes, quer se encontrem em solo africano ou não, constituem uma rede, embora não ainda um network. Mas quando Ruth Simms Hamilton, da Universidade de Michigan, lança a pergunta: Who we are and what we do? - Quem somos e o que fazemos? referindo-se à rede de africanos e seus descen- dentes dispersos por todo o mundo, realiza o primeiro movimento de um processo que poderá transformar a rede em rede de conexões. E não é por acaso que seu grupo de trabalho batizou com o nome Conexões a revista encarregada de ser o principal veículo de comunicação no interior dessa rede. Já em 1990 Ruth S. Hamilton divulgara preocupações e propostas, através da monografia: Criando um paradigma e uma agenda de pesquisa para estudos comparativos da dispersão dos povos africanos por todo o mundo. Hamilton deu expressão, enquanto porta-voz dessa rede, a preocupações coletivas e esboçou um percurso possível para a necessária transformação da referida rede em network.

A ênfase depositada na palavra necessária aponta para o importante papel reservado à consciência na construção dos networks, dado que deles devem decorrer mudanças significativas a nível pessoal e grupal. No referente à identidade pessoal, o sentimento de pertença a um grupo do qual os integrantes podem orgulhar-se, acarretará, necessariamente, mudanças individuais no que se refere à auto-imagem e auto-estima, com importantes decorrências no processo de conquista da cidadania. Quem não conhece a história do Patinho Feio que não sendo pato porém cisne, assenhorou-se da própria beleza e força ao reconhecer-se num grupo de iguais? $\mathrm{E}$ quem não experimentou, pelo menos uma vez, em maior ou menor grau, uma vivência como a dele, de estar com pessoas de determinado grupo e descobrir-se pertencente a outro? Ao realizar uma descoberta dessas reorganiza-se a gestal perceptual e nos percebemos seres novos para nós mesmos, vivendo num mundo igualmente novo. E melhor.

No Brasil, o debate das relações raciais, particularmente as que envolvem o segmento populacional composto de afrodescendentes, conquistou novos espaços em 1995, ano do tricentenário da morte de Zumbi dos Palmares. Em todo o país grupos de pequeno, médio e grande porte mobilizaram-se para cultuar a memória do herói negro, agora herói nacional. Nasceram novos grupos, gestados em distintas circunstâncias, com o objetivo tácito ou explícito de definir estratégias e políticas de combate à discriminação racial ou, em outras palavras, propor formas de valorização da África e de tudo e todos a ela relacionados. O cenário dos debates sobre políticas de ação afirmativa (PAA), cujos contornos tornavam-se mais definidos nesse ano, passou a ser ocupado por pessoas interessadas em conhecer experiências desenvolvidas em outros meios sociais, particularmente alguns países europeus, África do Sul e Estados Unidos. 
Não seria demais lembrar que o debate sobre PAA, desencadeado há muitas décadas em outros países, entre os quais os Estados Unidos (mais de 130 anos), somente ganhou o palco nacional há poucos anos. Segundo documento da Leadership Conference on Civil Rights, de 7 de março de 1995, ação afirmativa é um termo que engloba, além da simples extinção da prática discriminatória, qualquer medida adotada para corrigir e/ou compensar por atos discriminatórios passados ou presentes, bem como para prevenir novas ocorrências de discriminação ${ }^{2}$. Desta forma, a M é constituída de um conjunto de ações coordenadas em torno dos propósitos de (1) declarar ilegal o ato discriminatório; (2) estabelecer punições aos transgressores; (3) gerar múltiplos mecanismos de fiscalização e prevenção e (4) constituir agências de promoção social de segmentos discriminados. AAé, pois, a denominação geral de uma ampla rede de programas que reúnem estratégias destinadas a superar os efeitos da discriminação passada, promover ações compensatórias e, assim, promover oportunidades iguais para grupos que foram historicamente discriminados de forma negativa. No dizer de Santos (1996), o desafi o para este fim de milênio é construir uma democracia substantiva, é elaborar um modelo democrático onde o que conta é a igualdade de oportunidades e não a igualdade que afirma serem todos iguais perante a lei (p. 13).

Tive a oportunidade de acompanhar de perto e mesmo participar ativamente da constituição de alguns grupos voltados para o objetivo de definir estratégias e políticas de combate à discriminação racial e propor formas de valorização das diferenças. Um decreto presidencial criara o GTI - População Negra - Grupo de Trabalho Interrninisterial para Valorização da População Negra no Brasil, cuja coordenação foi confiada a Helio Santos; a Pró-Reitoria de Cultura e Extensão Universitária da Universidade de São Paulo, na pessoa do então Pró Reitor Jacques Marcovitch, criara o GPP - Grupo de Politicas Públicas para Valorização da População Negra, cujos principais objetivos incluíam o de elaborar propostas para valorização dos afrodescendentes na USP e na sociedade abrangente; o ^NEINB/USP - Núcleo de Pesquisas e Estudos Interdisciplinares do Negro Brasileiro, um dos Núcleos de Apoio à Pesquisa - NAPs da Pró-Reitoria de Pesquisa da USP passara a abrigar duas iniciativas: o Projeto de Criação do Banco de Dados (BDO) da Comunidade Negra Brasileira, coordenado por seu pro- ponente, Helio Santos, com a minha colaboração e um grupo interdisciplinar de pesquisa que receberia em setembro/97 o nome de Grupo de Estudos interdisciplinares das Ancestralidades Africanas e Cidadania GEAAC, composto de orientandos dos Programas de Mestrado e Doutorado da USP. Além de meus orientandos dos Programas de Pós-Graduação em Integração da América Latina (PROLAM) e Psicologia viriam a integrar esse grupo mestrandas da Faculdade de Educação.

A estrutura e dinâmica intragrupais e as relações que esse grupo e seus integrantes estabelecem com indivíduos ou grupos de abrangência variável no interior dos networks que tratam dessa temática constitui a matéria prima da refiexão que aqui realizo. Pretendendo tecer considerações sobre o GEAAC em particular sem perder a perspectiva de que o ocorrido nesse contexto particular possa ser generalizado, começo pelo relato da pré-história e história desse grupo.

A partir de 1994 esbocei a tentativa de trabalhar em grupo com meus orientandos de Mestrado e Doutorado, baseada nos seguintes pressupostos:

( l) um grupo é necessariamente mais inteligente, sensível e competente que qualquer um de seus integrantes;

(2) o longo processo de Mestrado/Doutorado articula-se necessariamente com a busca de conhecimento de si e com o processo de individuação dos envolvidos nessa tarefa, o que certamente não exclui o orientador;

(3) o grupo pode oferecer continência afetiva e suporte operacional para a realização ágil de trabalhos de excelência, o que acarreta ganhos pessoais, institucionais, econômicos e sociais;

(4) é possível e desejável relativizar o poder do orientador em favor da tarefa e das pessoas com ela comprometidas;

(5) pressuposto o objetivo de desenvolver pesquisas cujos resultados redundem em beneficio da vida social, o trabalho em grupo consiste, por si só, num exercício baseado nesse princípio.

Essa primeira tentativa de realização de um grupo de orientação não foi inteiramente bem sucedida, embora todos tenhamos usufruído beneficios dessa experiência. No período compreendido entre 1994/96, como resultado do esforço para articular os trabalhos de meus orientandos em torno de um eixo comum, organizei um grupo com os sete orientandos (Mestrado e Doutorado). Os temas que vinham sendo trabalhados indivi-

2 The Citizens' Commission on Civil Rights, em junho de 1984, reafirmando o definido em 1977, pela U.S Commission on Civil Rights. 
dualmente por eles impunham o desafio de definição do eixo temático: Acelí de Assis Magalhães estudava Funções Domésticas Femininas, Carla Mirella Mastrobuono ia em busca dos braços da Vênus: o resgate da agressividade feminina no saber jurídico e psicológico, Elias Boainain Jr. realizava o estudo teórico Transcentrando: tornar-se transpessoal - Elementos para uma aproximação entre a abordagem centrada na pessoa e a Psicologia Transpessoal, Márcia Maria Agatti Atalla estudava as relações entre avós e netos: Netos: $o$ olhar das avós, Peter Olusola Idowu queria saber a respeito d'A concepção de Deus na Tradição lorubá e em sua diáspora no Brasil e em Cuba, Ricardo Franlclin Ferreira realizava um estudo que foi denominado Grandes Questões: Veredas. A militância e o processo de subjetivação do homem contemporâneo, Sueli Pecci Passerini escrevia sobre $O$ fio de Ariadne: múltiplas formas narrativas e desenvolvimento infantil segundo a abordagem antroposófica de Rudolf Steiner e eu, orientadora deles também realizava um novo doutorado em Antropologia sob orientação de Kabengele Munanga, abordando o tema Mãe Negra: o significado iorubá da maternidade.

Nota-se facilmente o desafio de articular esses temas em torno de um único eixo. O máximo que conseguimos foi definir dois eixos, um principal e um secundário. O principal dizia respeito à metodologia e reunia todos os integrantes do grupo, dado que compartilhávamos a mesma postura política e epistemológica e utilizávamos recursos da abordagem qualitativa $\mathrm{O}$ secundário era constituído pela temática relativa aos Estudos sobre a Mulher e em torno desse eixo constituiuse o Clube da Luluzinha que reunia apenas as interessadas pela temática feminina e que continuaram participando do grupo abrangente. Acelí, Carla, Márcia e eu abordávamos temas em que a mulher ocupava lugar central. Sueli, trabalhando com narrativas, interessada particulannente pelas heroínas dos contos, mitos, lendas, fábulas e biografias, também pertencia ao Clube.

O grupo completo se reunia a cada três semanas e o Clube da Luluzinha, mensalmente. Essa experiência foi importante para todos que dela participaram, por uma ou outra razão. Para mim, serviu no sentido de reforçar convicções sobre o poder grupal e, a partir da identificação de causas do fracasso, poder tentar novamente. Do rol de itens responsáveis pelo fracasso interessa abordar aquele que me parece o mais importante: não tínhamos um bom eixo articulaclor dos trabalhos ou, em outras palavras, a tarefa coletiva fora definida a posteriori, artificialmente definida, digamos assim, no esforço por reunir os trabalhos de todos nós num projeto coletivo que de fato não existia.
A chegada de novos mestrandos e orientandos associou-se ao fato de eu ter reconhecido a mim mesma como integrante de um network que, tendo por objeto a Herança Africana, é articulado no Africana Studies and Research Center da Universidáde de Cornell, em Ithaca, New York. Pertencer a esse grupo favoreceu meu posicionamento, nítido e explícito, de trabalhar exclusivamente com matemática racial.

Meu novo grupo de orientandos que vinha se formando com o ingresso de novos pósgraduandos no instituto de Psicologia e PROLAM daUSP satisfazia a condição de trabalharem todos em torno do mesmo eixo temático foi enriquecido com a presença de mestrandas da Faculdade de Educação. Após alguns movimentos naturais de entrada e saída de integrantes, característicos dos grupos de tarefa, ficou constituído pelos seguintes membros: Alessandro de Oliveira dos Santos (Psicologia), abordando o tema Saúde e Sagrado. Um estudo sobre representações de doença no Candomblé, Denise Maria Botelho (PROLAM), Aya nini. Professores(as) no enfrentamento de práticas racistas em espaços escolares. Brasil e Cuba, Eliane dos Santos Cavalleiro (Educação), que no Mestrado tratou Do silêncio do lar ao silêncio escolar. Racismo, preconceito e discriminação na educação infantil, atualmente, doutoranda do Programa de Pós-Graduação em Educação da USP, desenvolve o tema Socialização: uma pesquisa geracional em famílas negras, José Tadeu de Paula Ribas (Psicologia), trata o tema Pessoa e Relações Interpessoais na Cosmovisão Iorubá e no Sistema Divinatório de Há, Juarez Fadei de Paula Xavier (PROLAM) desenvolve um Estudo comparativo de reelaboração da Religião Tradicional lorubá no Brasil e em Cuba, Maria Cristina da Silva (PROLAM) estuda a produção de artistas do Brasil e Cuba sobre a temática dos Orixás, Miriam Expedita Caetano (Psicologia) desenvolve pesquisa sobre o tema Educação e Relações Étnicas. Construindo uma pedagogia para a igualdade, Ricardo Franlclin Ferreira (Psicologia) narra uma história de lutas e vitórias. a construção da identidade de um afrodescendente no Brasil, eu me ocupando com o estudo de megatendências, particularmente esta da organização de pessoas em networks (redes de conexões) e com a temática das ancestralidades africanas e o processo de construção de identidade cidadania nos países da diáspora e Rosangela Costa Araújo (Educação) cujo trabalho recebeu título de Sou discípulo que aprende, meu mestre me dá lição. Tradição e educação entre os argoleiros baianos. Anos 80 e 90 e Valdeci Ri beiro dos Santos (Psicologia) aborda o tema Devires da Negritude em Porto Velho, Rondônia. 
No contexto das PAA se insere a produção desse GP que, além de realizar suas tarefas intrísecas, procura manter um sistema permanente de trocas que, necessariamente se estabelecen com grupos congêneres e no contexto geral de network constituído por todas as pessoas que trabalham conectadas em direção ao mesmo fim: transformar grilhões em alianças, promovendo qualidade de vida dos afrodescendentes.

Os componentes desse GP, oriundos de distintos cursos de graduação - Administração Educação, Jornalismo, Letras, História e Psicologia com ricas trajetórias pessoais e profissionais, vários deles ocupando postos de liderança em seus grupos, reunidos para melhor desenvolver seus projetos de mestrado e doutorado terminaram por constituir um grupo multidisciplinar com eixo temático fácil de explicitar: Ancestralidades Africanas e Construção da Identidade e da Cidadania nos países da Diáspora, amplo o suficiente para dar conta de todos os projetos que o compõem e que envolvem pesquisas de campo realizadas, algumas exclusivamente no Brasil, outras no Brasil e Cuba.

Este grupo, desde seu nascimento, passa a ocupar espaço no contexto de debates a respeito de estratégias e políticas de ação afirmativa (PAA) dado ao fato de que, além das tarefas que lhe são próprias enquanto grupo de pesquisadores vinculados a Programas de Pós-Graduação, mantém trocas permanentes com grupos congêneres no contexto geral do network constituído por todos os que trabalham para transformar grilhões em alianças, promovendo melhor qualidade de vida para os afrodescendentes.

O GEAAC, constituído no momento atual por uma porcentagem de $72,7 \%$ de pesquisadores afrodescendentes, todos pós-graduandos da USP, é, em si mesmo uma expressão de ação afirrnativa.

O cronograma de atividades, definido através de consenso grupal - o que faremos, quando, porque e para que - depende das necessidades individuais. Por exemplo, têm prioridade para receber tratamento grupal, projetos que, a curto ou médio prazo, serão submetidos a julgamento, seja por Banca de Qualificação ou Defesa, seja por Agências Financiadoras.

O GEAAC visa promover a capacitação profissional de seus integrantes de modo a habilitálos para (1) elaboração de projetos de pesquisa interdisciplinar, (2) acompanhamento de sua evo- lução (3) julgamento de projetos para emissão de pareceres, (4) reprodução dessa experiência grupal.

O enquadre operacional define os seguintes papéis: cada integrante elabora individualmente seu trabalho, depois o submete a julgamento no grupo. Isto é válido para todos, inclusive para a coordenadora, dado que o orientador dos integrantes do grupo é o próprio grupo e não uma única pessoa. Adotamos a sistemática de cada um eleger entre todos um leitor preferencial de seu trabalho, uma espécie de interlocutor principal. Todos lêem os trabalhos de todos e de todos se espera que contribuam para o aprimoramento do trabalho de cada um embora haja escolha do interlocutor principal. Cópias do trabalho a ser debatido são distribuídas com pelo menos uma semana de antecedência para que todos possam ler, julgar e colaborar, o que se realiza num clima onde predomina confiança mútua, interesse e respeito pela produção dos indivíduos e pelo ritmo de cada um, dentro dos limites institucionalmente determinados, na medida em que se trata de um processo de Pós-Graduação.

A coordenadora, embora não se desobrigue das sessões individuais de orientação, necessárias para todos a intervalos maiores, procura, no grupo, facilitar o processo em seus aspectos sócio-afetivos e sócio -operativos, obedecer rigorosamente as regras grupais e estar atenta para manter o clima de continência do grupo. O ambiente grupal propicia o respeito pelos conteúdos, formas e ritmos de cada integrante, pelo estágio e estilo pessoal de cada um, cujo desenvolvimento todos querem promover, dado que o desenvolvimento dos indivíduos é condição para o desenvolvimento do grupo e vice-versa. À coordenadora compete ainda, zelar para que no grupo se vivencie a máxima africana somos porque sou $e$ por sermos sou.

É interessante observar que o grupo, ao favorecer o desenvolvimento dos projetos individuais de seus integrantes, entre os quais me incluo, gera importantes ganhos secundários, tanto do ponto de vista sócio-operativo, como psicológico (sócio-afetivo). Do ponto de vista operativo possibilita precisar conceitos, aplicar teorias, desenvolver metodologia científica própria e elaborar, além de uma bibliografia comentada, textos que possam fornecer subsídios a outros pesquisadores e estudiosos da temática. Do ponto de vista psicológico, favorece o processo de individuação ${ }^{3}$

3 Utilizo o termo individuação, no sentido junguiano: o de realização completa do indivíduo, que supõe contínua ampliação da consciência e da personalidade através da atitude simbólica e da harmonização com seu centro mais profundo, harmonização das várias polaridades da personalidade, entre as quais consciente-inconsciente, corpo-psiche, individual coletivo (cf. GALLBACH, 1997, p. 35). 
de seus integrantes e fortalece as identidades na medida em que age sobre sua auto-imagem e autoestima, em decorrência de fatores cuja ação será melhor descrita ao tratarmos das relações entre identidade e pertença a grupos de trabalho (GT) e networks (NW).

O que se visa é a preponderância de um ambiente de continência grupal para os conteúdos e formas. Não uma atitude de julgamento racional, mas de aceitação, confiança e estímulo ao desenvolvimento do potencial de cada um e do coletivo. O GP favorece o desenvolvimento individual em contexto grupal enquanto favorece o desenvolvimento do próprio grupo enquanto organismo social.

O fecundo tema articulador dos trabalhos gerou ganhos adicionais desde o início das atividades, tais como a formulação de propostas de workshops, participação em congressos, encontros, seminários e outras oportunidades para o debate e reflexão. Favoreceu ainda, a formação de parcerias no interior do próprio grupo com vistas a favorecer tratamento interdisciplinar de temas emergentes.

Lembrando que a principal diferença entre grupo e agrupamento reside no fato de ser este último estruturado de tal modo que cada um de seus integrantes não é significativo para os demais (PICHÓN-RIVIÈRE, 1977), propõe-se a criação de condições que favoreçam outros vínculos além dos que normalmente se estabelecem no interior da tradicional relação orientador-orientando, com ritmo de encontros muitas vezes irregular, determinado na maioria das vezes pelas necessidades do orientando que, desaparecido, somente reaparece com os prazos prestes a estourar e o trabalho quase desmoronando com lacunas, distorções, equívocos e erros de toda ordem, colocando por vezes o orientador diante de uma tarefa desesperadoramente impossível.

A estrutura grupal favorece compartilhar tempo, lugar e um campo psicológico onde se articulam as emoções, vivências, idéias e conhecimentos, através da interação. Não sendo o vinculo apenas dual, o grupo acompanha com dedicação o trabalho de cada um de seus integrantes, inclusive o do coordenador. Uma das mais importantes diferenças entre o trabalho de orientação realizado individualmente e em grupo é o fato de que no primeiro caso quem orienta é uma pessoa com todas suas limitações e, no segundo, quem orienta é um grupo interdisciplinar. As implicações disso, são fáceis de deduzir.

Dos fatores sócio-afetivos atuantes vale mencionar as relações interpessoais - contatos um a um, dois a dois etc. - que, uma vez estabelecidas entre os participantes, garantem a possibili- dade do grupo oferecer continência a cada um e a todos e este é um aspecto importante quando se trata de enfrentar fantasmas tais como sou incompetente para realizar essa tarefa, não vou ser capaz, não vou dar conta dos prazos, não saberei enfrentar o furor da Banca Examinadora e muitos outros associados ao rebaixamento da auto-estima e à auto-imagem negativa, condições amplificadas no grupo de afrodescendentes que, dadas as condições históricas, chegam, vitoriosos, à Academia.

Abordar a temática racial num país como o Brasil que, apesar de constituído de uma parcela majoritária de afrodescendentes afirma e reafirma a hegemonia de valores europeus, favorece a emergência de sentimentos e emoções associados às feridas narcísicas dos afrodescendentes e à culpa dos brancos. Raiva, ressentimentos, melancolia, tristeza, hostilidade emergem associados aos conteúdos teóricos e históricos e isso demanda um clima propício à consecução da tarefa. É necessário um bom grupo-continente e os encontros individuais para orientação podem complementar e favorecer ainda mais o processo. Embora a proposta não seja e nem poderia ser a de realização de uma terapia de grupo, não se pode ignorar a eficácia terapêutica dos grupos, se entendemos por condições terapêuticas as capazes de promover a individuação e a ampliação da consciência.

Não buscando apenas a inteligência conceitual mas, para além dela, a compreensão, o discernimento, a sabedoria, entendemos que o conhecimento intelectual deva colocar-se a serviço da Ética e da Moral. As emoções suscitadas pelos desafios da tarefa tornam-se mais suportáveis e passíveis de superação em grupos que oferecem bom continente emocional. Acha-se mais do que suficientemente constatado que quando se tem confiança na colaboração e suporte dos outros, torna-se mais fácil lidar com desafios existenciais e emoções que os acompanham. A isto chamamos continência grupal e é impossível atingir o mesmo grau de suporte emocional num trabalho de orientação individual.

Analogia corrente para esse fato é a do grupo como vaso alquímico para a elaboração e transformação de conteúdos fantasmáticos e da ansiedade que acompanha todos os processos de crescimento. O grupo traz acolhimento e proteção. Será vaso alquímico para elaboração e transformação de imagens se for competente para conter, além dos conceitos, a emoção e os sentimentos. Os parceiros, ao se disporem a aceitar lacunas, falhas e distorções próprias do processo, facilitam o enfrentamento de desafios maiores.

A observação da psique trabalhando em mim e nos outros também potencializa a confiança. $\mathrm{O}$ 
processo vivido por um integrante do grupo constitui-se em modelo, gerando força e coragem para ousar, para arriscar. Como cada um vive por empatia a condição dos outros, vai se fortalecendo no grupo, pouco a pouco, a confiança e a coragem.

Mas nem sempre tudo deslisa suavemente. Alguns incidentes ocorridos ao longo desses anos do GEAAC apontam para a possibilidade de que a elaboração de conteúdos fantasmáticos talvez não seja sempre possível. Relações entre brancos e negros, gravadas a ferro e fogo na subjetividade, fortemente marcadas pelo exercício da injustiça, do jugo e da exploração, construídas, confirmadas e reconfirmadas ao longo da história individual, por vezes resistem às mudanças que o grupo poderia (e se propõe a) realizar. Observei a possibilidade de ocorrência de uma espécie de “enrijecimento" que leva pessoas à dificuldade de viver uma experiência diversa das anteriores. Em outras palavras, nesse contexto, diante de dificuldades comuns, inerentes à realização de trabalhos acadêmicos, o processo transferencial e contra-transferencial poderá trazer para a relação orien-tador/orientando ou mesmo orientando/orientandos antigas experiências dolorosas de interação não elaboradas devidamente e disto decorrer um "sangramento" das feridas narcísicas. Nessa circunstância o processo de avaliação e crítica do trabalho adquire caráter persecutório e tornar-se quase intolerável para o pesquisador, desencadeando em vários integrantes do grupo, simultaneamente, uma verdadeira tempestade de sentimentos e ressentimentos. Culpa, raiva, medo, insegurança passam a ocupar o palco nesse novo contexto em que, abalada a confiança e questionado o vínculo, vivese a situação num “como se” de características exatamente avessas àquelas que se pretendeu criar. Caso a situação não seja administrada a contento, incidentes dessa natureza, dependendo de sua intensidade e porte, poderão acarretar cisma grupal ou perda de integrantes. Acontecimentos dessa natureza são, felizmente, raros.

O GP inclui o aprender como se faz e a vivência dessa participação estimula cada integrante a reproduzi-la em outros espaços de ensino. Para melhor refletir sobre essa dinâmica é interessante recorrer ao pressuposto de que a ação do "self" enquanto entidade transpessoal pode manifestar-se através de uma espécie de incorporação propiciada pelo grupo de modo a favorecer a manifestação da sabedoria em mim e no outro (JUNG apud GALLBACH, 1977).

Embora não seja possível, neste contexto, uma apresentação mais completa das contribuições teóricas e sua possível articulação para a leitura esclarecedora dos dinamismos estabelecidos entre identidade e pertença a grupos de pequeno porte como o GP aqui descrito e a networks como o aqui mencionado, teço algumas considerações sobre o tema.

A pergunta quem sou eu? inclui sempre entre as respostas algumas referências a respeito da pertença a grupos: sou aquele que pertence à família Silva, sou funcionário da Empresa Cores, professo areligião messiânica e assim por diante... Cada um de nós se apresenta enquanto integrante de grupos de pequeno, médio e grande porte. Num passado não muito remoto, antes desse extraordinário e rápido progresso da informática e das telecomunicações, dificilmente se fazia um reconhecimento de si como pertencente a grupos capazes de superar desafios impostos pela distância geográfica. Mas o desenvolvimento tecnológico criou a diferenca: em tomo de objetivos comuns constituem-se agora os networks que associam pessoas cujas afinidades e interesses ignoram barreiras geográficas.

A dinâmica dos megagrupos, embora pressuponha a possibilidade das interações via internet e outros meios de comunicação à distância, não exclui a possibilidade de contatos interpessoais face a face nem a de organização de subgrupos de trabalho de tamanho variável. Pelo contrário. De verdade trabalhamos em parceria com companheiros que conosco compartilham tempo e espaço, sem perder de vista o fato de que nós dois ou nós três ou nós cinco... ou nós todos, integrantes deste ou daquele grupo de pequeno ou médio porte realizamos parte de um trabalho amplo desenvolvido sob a responsabilidade de um grupo muito grande e que, embora não haja - e geralmente não há - possibilidade de reunir fisicamente todos esses trabalhadores, constituímos um grupo.

Conforme assinalei, não cabe realizar uma articulação teórica mais completa no presente contexto. Sugiro ao leitor interessado a leitura de PICHÓN-RIVIÈRE (1977) que, situado nos domínios da etnopsicanálise, fornece excelente instrumental de trabalho em grupos de todo porte desde que favorece a identificação e compreensão de dinamismos favoráveis à consecução de objetivos individuais e coletivos quando se consegue criar um ECRO - esquema conceitual, referencial e operativo-compartilhado. Igualmente úteis para aguçar a acuidade de leitura teórica desse processo são os trabalhos de PIERRE LÉVY (1994) que, ao tratar do conceito de inteligência coletiva em muito contribui para a leitura das relações que se estabelecem entre pequenos grupos e networks. A respeito deste último conceito encontramos em LIPNACK \& STAMPS (1992) um bom ponto de partida. Finalmente, quanto à noção de identidade e suas metamorfo- 
ses, temos no brasileiro CIAMPA (1987) uma das mais lúcidas formas de tratamento.

Sob a Ética que construí a partir da leitura desses autores e atenta ao processo grupal observado nesses poucos anos de trabalho do GEAAC, vi efeitos do trabalho na auto-estima e auto-imagem dos integrantes do grupo; aumento de eficácia individual e grupal de resposta às demandas dos Programas de Pós-Graduação (quando comparo com minha experiência anterior); maior capacitação para o exercício da docência universitária e da pesquisa; conscientização de que a inteligência coletiva e os networks constituem-se a partir do esforço cotidiano, muitas vezes anônimo, aparentemente restrito e quantas vezes acanhado, de cada um de nós.

\begin{abstract}
Tecendo a manhã
João Cabral de Melo Neto

Um galo sozinho não tece uma manhã. ele precisará sempre de outros galos. De um que apanhe esse grito que ele e o lance a outro, de um outro galo que apanhe o grito que um galo antes e o lance a outro; e de outros galos que com muitos outros galos, se cruzem os fios de sol de seus gritos de galo, para que a manhã, desde uma teia ténue, se vá tecendo, entre todos os galos.

E se encorpando em tela, entre todos, Se erguendo tenda, onde entrem todos, Se entretendendo para todos, no toldo (a manhã) que plana livre de armação. A manhã, toldo de um tecido tão aéreo que, tecido, se eleva por si: luz-balão.
\end{abstract}

\begin{abstract}
This article describes and discasses the experience of lhe Group of Interdisciplinary Studies of African Ancestries and Citizenship, a group that supervises Master and Doctoral researches in lhe University of São Paulo, trying to contributo lo lhe maturation of lhe debate on lhe need of affirrnative action policies that value Africa, Africans and Afro-descendants. To present part of lhe experience of this group of studies, lhe following topics are addressed: (a) the concept of network; (b) lhe relations between personal identity and belonging to networks organised around lhe racial thematics.
\end{abstract}

Key-words: Afro-descendants, affirmative action, citizenship.

\section{REFERÊNCIAS BIBLIOGRÁFICAS}

ANDERSON, D. E. Civil Rights. USA, Communication Consortium Media Center, Washington, 1984.

CEAA (Centro de Estudos Afro-asiáticos). Os números da cor. Boletim Estatístico sobre a Situação Sócio-Economica dos Grupos de Cor no Brasil e suas regiões. Rio de Janeiro, 1995.

CIAMPA, A. d. C. A estória do Severino e a história da Severina. Um ensaio de Psicologia Social. SãoPaulo, Brasiliense, 1987.

Discurso do Presidente da Republica Fernando Henrique Cardoso na Abertura do Seminário internacional. Multiculturalismo e racismo. o papel da ação afirmativa nos estados democráticos contemporâneos. Brasília, Palácio do Planalto, julho/1996.

GALLBACH, M.R. Grupo de vivência de sonhos. uma investigação sobre formas de trabalho com sonhos. São Paulo, 1997. [Tese de Doutorado - Instituto de Psicologia da Universidade de São Paulo].

GRUPO DE POLÍTICAS PÚBLICAS/PR CEUSP. Dados para a formulação de políticas públicas visando à melhoria das condições de vida do negro brasileiro. Tricentenário da Morte de Zurnbi dos Palmares. São Paulo, Pró-Reitoria de Cultura e Extensão da USP, 1955. (Jornal daUSP, Ano XII, n.371).
GUIMARAES, M. P. Políticas afirmativas esua aplicabilidade. São Paulo, OAB (Seção São Paulo), 1996.

GUIMARÃES, A. S. Políticas públicas para a ascenção dos negros no Brasil: argumentando pela ação af rmativa. Caxambu, ANPOCS, out/96. (XX Encontro Anual da ANPOCS, inédito).

GUIMARÃES, A. S. (Org.) Racismo e restrição de direitos individuais. a discriminação racial publicizada. (Segundo Relatório de Pesquisa, grant. 950-1218 da F. Ford,processo 300494/ 88-2 CNPq. Salvador, junho/96. (inédito)

LEVY, P.; AUTHIER, M. As árvores de conhecimentos. São Paulo, Escuta, 1995.

LEVY, P. As tecnologias da inteligência: o futuro do pensamento na era da informática. Rio de Janeiro, Ed.34, 1993.

LEVY, P. O que é o virtual? São Paulo, Ed.34, 1996.

LEVY, P. La intelligence collective. Pour une anthropologie du cyberspace. Paris, LaDécouverte, 1994. LIPNACK, J.; STAMPS, J. Networks. Redes de Conexões. São Paulo, Ed. Aquariana, 1992.

MINISTÉRIO DO PLANEJAMENTO E ORÇAMENTO (IBGE). Cor da população. Síntese de indicadores 1982/1990. Rio de Janeiro, IBGE, 1995. 
MUNANGA, K. Estratégias e políticas de combate à discriminação racial. São Paulo, EDUSP, 1996.

NEVES, M. Entre subintegração e sobreintegração: a cidadania inexistente. Dados. Revista de Ciencias Sociais, 37 (2), Rio de Janeiro, Iuperj, 1994.

NEVES, M. Estado democrático brasileiro e discriminação positiva: um desafio para o Brasil. Paper apresentado no Seminario Internacional multiculturalismo e Racismo: o papel da ação af rmativa nos Estados Democráticos Brasileiros. Brasília, julho/96.

PICHON-RIVIERE, E. Elprocesogrupal: delpsicoanalisis a la psicologia social. Buenos Aires, Ed. NuevaVisión, 1977.

PICHÓN-RIVIERE, E. Teoria del Vinculo. Buenos Aires, Ed. NuevaVisión, 1980.

Programa Nacional de Direitos Humanos / Fernando Henrique Cardoso. Brasília, Presidência da República, Secretaria de Comunicação Social, Ministério da Justiça, 1996.
RIBEIRO, R. I. Ação educacional na construção do novo imaginário infantil sobre a África. In: MUNANGA, K. Estratégias e politicas de combate à discriminação Racial. São Paulo, EDUSP, 1996.

RIBEIRO, R.I. Alma africana no Brasil. Os iorubás. São Paulo, Ed. Oduduwa, 1996.

RIBEIRO, R. I. Convergindo esforços para a valorização dos brasileiros afro-descendentes (e para a construção de um amanhã radiante). Paper apresentado no Seminário Internacional Multicultuialismo e Racismo: o papel da ação afirmativa nos Estados Democráticos Brasileiros. Brasília, julho/96.

SANTOS, H. Uma teoria para a questão racial do negro brasileiro. A Trilha do Círculo Vicioso. São Paulo em perspectiva, Revista da Fundação SEADE,8 (3), jul/set, 1994.

XAVIER, J. T. P. Considerações sobre o Congresso Continental dos Povos Negros das Américas. Artigo inédito, 1995. 